\title{
OS MATERIAIS DE ENSINO E SEUS TRATAMENTOS NOS GRUPOS ESCOLARES DE SERGIPE (1911-1931)
}

\author{
Jéssica Cravo Santos Bernardino \\ Universidade Federal de Sergipe \\ jessicacravo@hotmail.com
}

\begin{abstract}
Resumo
Neste artigo são apresentadas algumas considerações sobre os materiais de ensino prescritos ao ensino dos saberes elementares matemáticos no curso primário sergipano, durante o período de 1911 a 1931, segundo os princípios pedagógicos em voga, isto é, buscou-se compreender se em meio ao processo modernizador republicano que vinha se instaurando em todo o país, foram suscitadas alterações no modo como o ensino primário vinha se instaurando no Estado, a fim de desvendar a funcionalidade de propostas e práticas modernas apontadas na legislação. Para alcançar o propósito do texto foram examinadas fontes de pesquisa como: Regulamentos, Leis, Decretos e Programas de Ensino, que puderam subsidiar a investigação. Como fundamentação teórica, foram adotados autores como Calkins (1886/1950) e Valdemarin (2006), para entendimento do método de ensino intuitivo ou lições de coisas; Souza (2006), Azevedo (2009) e Nascimento (2012), para informações sobre os Grupos Escolares; e Pais (2011), Pinheiro (2013) e Valente (2008), para pincelar informações sobre os materiais. Com base na investigação realizada constatou-se em Sergipe, referências à pedagogia nova, baseada pelo método de ensino intuitivo, tendo por princípios o ensino pelos sentidos, pela realidade e pela intuição como principal instrumento de aprendizagem, e tomando os materiais de ensino como elementos cruciais da instrução, seja para acurar a observação ou para atingir o raciocínio pelo tato e manipulação.
\end{abstract}

Palavras-chave: Materiais de Ensino. Pedagogia Nova. Método de Ensino Intuitivo. Grupos Escolares Sergipanos.

\begin{abstract}
In this article we present some considerations about the teaching materials prescribed for the teaching of elementary mathematical knowledge in the Sergipe primary course during the period from 1911 to 1931 , according to the pedagogical principles in vogue, that is, we tried to understand if in the middle of the process Republican modernization that was being established throughout the country, changes were made in the way that primary education was being established in the State, in order to unveil the functionality of modern proposals and practices pointed out in the legislation. In order to achieve the purpose of the text, we have examined research sources such as: Regulations, Laws, Decrees and Teaching Programs, which could subsidize research. As a theoretical basis, authors such as Calkins (1886/1950) and Valdemarin (2006) were adopted, in order to understand the intuitive method of teaching or lessons of things; Souza (2006), Azevedo (2009) and Nascimento (2012), for information on the School Groups; and Pais (2011), Pinheiro (2013) and Valente (2008), to brush information about the materials. Based on research carried out in Sergipe, references to the new pedagogy, based on the intuitive method of teaching, were based on principles of teaching by the senses, reality and intuition as the main learning instrument, and taking teaching materials as elements crucial to instruction, whether to enlighten observation or to achieve reasoning by touch and manipulation.
\end{abstract}

Keywords: Teaching Materials. New Pedagogy. Intuitive Teaching Method. Sergipanos School Groups. 


\section{INTRODUÇÃO}

No presente artigo são apresentadas algumas considerações a respeito dos materiais de ensino ${ }^{1}$ prescritos para o ensino dos saberes elementares matemáticos $(\mathrm{SEM})^{2}$ no curso primário sergipano durante o período de 1911 a 1931, em que são enfatizados seus tratamentos segundo os preceitos pedagógicos da época.

Cabe destacar que a temática exposta contempla recorte de uma pesquisa maior, vinculada ao Programa de Pós-graduação em Ensino de Ciências e Matemática da Universidade Federal de Sergipe ${ }^{3}$, inserida no âmbito do Grupo de Pesquisa de História da Educação Matemática no Brasil (GHEMAT) ${ }^{4}$, e buscou contribuir para a produção de conhecimento histórico acerca do ensino primário em Sergipe.

O marco de investigação aqui estabelecido, trata-se, segundo Azevedo (2009), do período de modernização pedagógica no Estado à luz da incorporação do método de ensino intuitivo, no qual os materiais de ensino são prescritos mediante reformas e métodos educacionais empregados pela legislação escolar. Tais movimentações alteram o modo como a educação era estabelecida, de acordo com as finalidades em que os saberes e os materiais eram propostos.

Em acordo com Chervel (1990), de um lado, novos objetos, impostos pela conjuntura política ou pela renovação do sistema educacional, tornam-se objeto de declarações claras e circunstanciadas e, de outro, cada professor é forçado a se lançar por sua própria conta em caminhos que ainda não foram trilhados ou a experimentar as soluções que the são aconselhadas.

Dessa maneira, neste artigo buscou-se compreender se em meio ao processo modernizador republicano que vinha se instaurando em todo o país, foram suscitadas

\footnotetext{
${ }^{1}$ Considerados como todo e qualquer objeto que pode ser utilizado como instrumento facilitador no processo de ensino-aprendizagem dos saberes elementares matemáticos presentes nas matérias/disciplinas Aritmética e Desenho no curso primário sergipano.

${ }^{2}$ Considerados como aqueles conteúdos da matemática escolar presentes para ensino no curso primário.

${ }^{3}$ Pesquisa de mestrado em Ensino de Ciências e Matemática, intitulada: "Materiais de Ensino e os Saberes Elementares Matemáticos, Sergipe (1911-1931)", realizado sob a orientação da Profa. Dra. Ivanete Batista dos Santos.

${ }^{4}$ Os integrantes do Grupo de Pesquisa de História da Educação Matemática no Brasil (GHEMAT), vêm desenvolvendo pesquisas acerca da matemática escolar elementar, que a nível nacional, serve ao projeto "A Constituição dos Saberes Elementares Matemáticos: a Aritmética, a Geometria e o Desenho no curso primário em perspectiva histórico-comparativa, 1890-1970". Para maiores detalhes, acessar: http://www.unifesp.br/centros/ghemat/paginas/about_ghemat.htm
} 
alterações no modo como o ensino primário vinha se instaurando no Estado sergipano, fazendo-se para tal, uso de documentos da legislação.

Por se tratar de uma pesquisa de cunho histórico-bibliográfico em que necessário estabelecer uma ponte entre o presente e o passado, o exame das fontes torna-se prática imprescindível, pois:

O trabalho historiográfico não é atinente à verdade, mas a certeza. Esta distinção não está situada na dicotomia entre o verdadeiro e o falso, mas entre o acertado e o não acertado, ou melhor, entre os diversos graus de acertos possíveis. Sem referência às fontes, de uma pesquisa sobre a possibilidade de acertar se passa a uma pesquisa sobre o verdadeiro (RAGAZZINI, 2001, p.16).

Além disso, buscou-se também desvendar a "funcionalidade" de propostas e práticas prescritas segundo a legislação, visto que,

O discurso político e educacional produzido nas últimas décadas do Império, estabelece estreitos vínculos entre as propostas de inovação metodológica e a difusão do ideário liberal republicano, destacando-se a utilização das lições de coisas ou método intuitivo como estratégia de intervenção na sala de aula, locus específico da instrução e da mudança das práticas pedagógicas, adequando a escola ao projeto político modernizador. (VALDEMARIN, 2006, p. 90).

Em meio a tal modernização do ensino, faz-se necessário iniciarmos pela criação e consolidação dos Grupos Escolares em Sergipe, considerados como propulsores iniciais de mudanças para fins da melhoria educacional que se intentava alcançar.

\section{ESPAÇO ESCOLAR DE CIVILIZAÇÃO E INSTRUÇÃO: OS GRUPOS ESCOLARES SERGIPANOS}

Segundo Frago e Escolano (1998 apud LIMA, 2007), a arquitetura escolar pode ser considerada como uma espécie de discurso que institui, em sua materialidade, um sistema de valores - ordem, disciplina e vigilância - marcos para a aprendizagem sensorial e motora, em que toda uma semiologia cobre diferentes símbolos estéticos, culturais e ideológicos.

Nesse sentido, destaca Carvalho (2003), que tão logo proclamada a República, governantes do Estado de São Paulo investiram na organização de um sistema de ensino modelar, desenvolvido a partir da Escola Modelo (anexa à Escola Normal), inaugurada com a Reforma Caetano de Campos, onde os futuros mestres poderiam ver como as crianças eram manejadas e instruídas, tendo em vista que o modo de aprender era centrado na visibilidade 
e imitabilidade das práticas pedagógicas, cujo fim era a propagação dos métodos de ensino e práticas de organização da vida escolar.

Assim, o olhar torna-se elemento crucial na instrução do professorado, em que "[...] nessa pedagogia como arte, como saber-fazer, a prática da observação modula a relação ensino-aprendizagem, instaurando o primado da visibilidade" (CARVALHO, 2003, p. 83).

Em consonância a tal reforma, criaram-se Grupos Escolares, vistos como instituições que condensariam a modernidade pedagógica, ofertando ensino seriado, classes homogêneas e reunidas em um mesmo prédio (sob uma única direção), métodos pedagógicos modernos e monumentalidade de edifícios, fazendo a Instrução Pública Primária representar o signo do Progresso.

Em Sergipe, afirma Nascimento (2012), que apesar dos preceitos modernos, durante as duas primeiras décadas do regime republicano, a escola primária de cadeiras isoladas, ou escola singular, continuou a ser o modelo predominante da instrução pública das crianças, sendo essas escolas de dois tipos: a escola elementar e a escola complementar ${ }^{5}$.

Segundo Nascimento (2012), uma das distinções entre ambas as escolas está na remuneração dos professores, isto é, a escola complementar contava com professores que recebiam melhores salários em relação ao oferecido aos professores da escola primária elementar.

Entretanto, a implantação efetiva da escola primária nos Grupos Escolares Sergipanos - GES, já a muito ressaltada, deu-se por meio do Decreto N. 563, que vigorou em 12 de Agosto de 1911, estabelecendo uma nova organização para o ensino no Estado. Porém, cabe destacar que "[...] na prática, definiu dois principais modelos adotados doravante: a escola isolada e a escola seriada, funcionando esta última nos grupos escolares" (NASCIMENTO, 2012, p. 213).

Para o autor, os GES também eram vistos como espaço de excelência para a aprendizagem em sentido amplo, pois, além da formação cívica posta em relevo, havia a preocupação de fixar às crianças, “[...] valores relativos ao cumprimento do dever, ao culto da responsabilidade, do amor, do bem, da solidariedade, do respeito às leis, dos valores morais (NASCIMENTO, 2012, p. 229).

\footnotetext{
${ }^{5}$ As escolas isoladas ou singulares, tratavam-se de escolas de classes autônomas e funcionamento unitário, reservadas, em grande parte, a alunos de bairro muito pobre, já que os grupos escolares estavam dispostos apenas em cidades e capitais. Assim, classificadas em $1^{\mathrm{a}}, 2^{\mathrm{a}}, 3^{\mathrm{a}}$, e $4^{\mathrm{a}}$ entrâncias ou categorias, respectivamente: povoados, vilas, cidades e capitais, "[...] as escolas singulares são destinadas, umas, ao sexo masculino, outras, ao feminino, outras, aos dois sexos, promiscnamente, chamados, neste caso, mixtas" (SERGIPE, 1912, p. 4).
} 
Essa modalidade de escola primária, conforme Souza (2006), foi implantada pela primeira vez em 1893, no estado de São Paulo, e representou uma das mais importantes inovações educacionais ocorridas no final do século XIX, tendo em vista sua repercussão em diversos estados da federação.

Tratava-se de um modelo de organização do ensino elementar mais racionalizado e padronizado com vistas a atender um grande número de crianças, portanto, uma escola adequada à escolarização em massa e às necessidades da universalização da educação popular. Ao implantá-lo, políticos, intelectuais e educadores paulistas almejavam modernizar a educação e elevar o país ao patamar dos países mais desenvolvidos (SOUZA, 2006, p. 35).

Em acordo com a autora, pode-se dizer que a escola primária foi "(re) inventada", e consigo foram instituídas novas finalidades, outra concepção educacional e outra organização de ensino. Mudanças relevantes ocorreram no quadro geral da instrução pública primária no Brasil, tendo como destaque a instauração dos Grupos Escolares, além disso:

O método individual cedeu lugar ao ensino simultâneo; a escola unitária foi, paulatinamente, substituída pela escola de várias classes e vários professores, o método tradicional cedeu lugar ao método intuitivo, a mulher encontrou no magistério primário uma profissão, os professores e professoras tornaram-se profissionais da educação (SOUZA, 2006, p. 35).

Destaca Azevedo (2009) que em Sergipe, a implantação dos grupos foi iniciada na capital (Aracaju), ocorrida no governo de José Rodrigues da Costa Dória (1908-1911), com a participação do professor paulista Carlos Silveira em 1911, e expandida para outras cidades do Estado, como: Propriá, Vilanova (atual Neópolis), Capela, São Cristóvão, Estância, Boquim, Lagarto e Annápolis (atual Simão Dias), identificadas essas até o ano de 1925, mas que se expandiram continuamente.

Dessa maneira, os Grupos Escolares em Sergipe fizeram parte de um processo modernizador e civilizatório inaugurando a escola dita moderna, onde,

[...] novas concepções de tempo e espaço aparecem; a cultura da escrita impõe-se na busca por uma suposta superioridade, assim como outros atos cotidianos em que a formação e a difusão de determinados valores e crenças, hábitos e saberes são postos para que sejam trabalhados com os alunos, objetivando-se que através deste, toda a sociedade fosse atingida. (AZEVEDO, 2009, p. 30). 
Assim, é possível dizer que a escola moderna se caracteriza, entre outros aspectos, pela reforma de métodos adotados no ensino primário sergipano, realizado "[...] por processos obsoletos e condemnados pela moderna Pedagogia" "(SERGIPE, 1911, p. 13).

Destaca Saviani (2005) que, diferente da visão tradicional ${ }^{7}$, a concepção pedagógica renovadora apoiava-se numa visão filosófica baseada na existência, na vida e na atividade em que o homem é considerado completo desde seu nascimento e inacabado até morrer.

Do ponto de vista pedagógico o eixo se deslocou do intelecto para as vivências; do lógico para o psicológico; dos conteúdos para os métodos; do professor para o aluno; do esforço para o interesse; da disciplina para a espontaneidade; da direção do professor para a iniciativa do aluno; da quantidade para a qualidade; de uma pedagogia de inspiração filosófica centrada na ciência lógica para uma pedagogia de inspiração experimental baseada na biologia e na psicologia (SAVIANI, 2005, p. 33).

Nesse sentido, os Grupos Escolares em Sergipe contribuíram para elevar o padrão de qualidade dos serviços públicos, em meio aos novos preceitos, uma vez que antes da instalação de tais grupos, só se encontravam no Estado escolas mal distribuídas, sem obedecer a critérios pedagógicos modernos de ensino, tendo como base métodos tradicionais, isto é, a aprendizagem era fundamentada exclusivamente na memorização, priorizando a abstração, valorizando a repetição ao invés da compreensão, impondo o conteúdo sem a efetiva participação do aluno.

Ressalva Azevedo (2009) que o uso de recursos didáticos modernos e de uma nova metodologia, além de profissionais com melhor formação (professores normalistas), tornaram-se necessários para se estabelecer ideais e valores republicanos. Em conformidade, grande importância é atribuída ao mobiliário e ao material didático, pois, “[...] jamais poderão ser colhidos os benefícios [...] se não forem as escolas dotadas do material pedagógico necessário e indispensável ao ensino prático" (AZEVEDO, 2009, p. 187).

É possível identificar, no que apresenta a citada autora, pedidos e agradecimentos sintéticos de diretores de Grupos Escolares à Diretoria da Instrução Pública, com relação aos materiais de ensino recebidos em respectivos espaços escolares, podendo-se destacar entre

\footnotetext{
${ }^{6}$ Nesta investigação, optou-se por adotar a grafia original da época na transcrição do que dizem as fontes, a fim de possibilitar ao leitor uma aproximação ao ensino de tempos passados.

7 "A denominação "concepção pedagógica tradicional" ou "pedagogia tradicional" foi introduzida no final do século XIX com o advento do movimento renovador que para marcar a novidade das propostas que começaram a ser veiculadas, classificam como "tradicional" a concepção até então dominante. Assim, a expressão "concepção tradicional" subsume correntes pedagógicas que se formularam desde a Antiguidade, tendo em comum uma visão filosófica essencialista de homem e uma visão pedagógica centrada no educador (professor), no adulto, no intelecto, nos conteúdos cognitivos transmitidos pelo professor aos alunos, na disciplina, na memorização" (SAVIANI, 2005, p. 31).
} 
estes: réguas, esquadros, mapas do sistema métrico do Brasil, Cartas de Parker, contadores mecânicos, coleções de Desenho de Olavo Freire $1^{\circ}, 2^{\circ}, 3^{\circ}$ e $4^{\circ}$, entre outros.

Entretanto, nem todos os GES dispuseram do recebimento de materiais de ensino indispensáveis a instrução primária. Mas, de todo modo é possível afirmar que o Governo do Estado procurava, de alguma forma, estabelecer um padrão de escola que, apesar de nem sempre ter possuído condições ideais de funcionamento, respaldava na criação de uma cultura introduzida e cultivada, pois, como bem diz Julia (2001), a cultura escolar permite a análise precisa de relações conflituosas e pacíficas que ela mantém a cada período de sua história, com o conjunto das culturas que lhe são contemporâneas.

\section{MATERIAIS E PEDAGOGIAS: UM ENTRELAÇO SOB DUAS DIREÇÕES}

Diante do exposto, pode-se notar que a criação dos grupos escolares esteve diretamente atrelada a um movimento de renovação pedagógica contrário ao caráter abstrato e pouco utilitário da instrução, em que se procurava mudar o modo como o ensino vinha sendo tratado, por um novo método de ensino: “[...] concreto, racional e ativo, denominado ensino pelo aspecto, lições de coisas ou ensino intuitivo" (VALDEMARIN, 2006, p. 91, grifos da autora).

Dessa maneira, para identificar os preceitos pedagógico no Estado sergipano, foi realizado um exame sobre Regulamentos, Leis, Decretos e Programas de Ensino, cujo propósito consistiu em compreender os métodos pedagógicos, para se averiguar o(s) possíveis uso(s) dado aos materiais de ensino dos saberes elementares matemáticos. Assim, as fontes analisadas são destacadas a seguir:

* Regulamento de 1912 - Lei N. 605 de 24 de Setembro de 1912.

* Decreto N. 571 de 19 de Outubro de 1912.

* Programma para o Ensino Primario, especialmente para os Grupos Escholares, 1912.

* Lei N. 663 de 28 de Julho de 1914.

* Programma para o curso primario nos Grupos Escolares e Escolas Isoladas do Estado de Sergipe, 1915.

* Regulamento de 1916 - Decreto N. 630 de 24 de Abril de 1916.
* Programma para o curso primario nos Grupos Escolares e Escolas Isoladas do Estado de Sergipe, 1916.

* Programma para o curso primario nos Grupos Escolares e Escolas Isoladas do Estado, 1917.

* Lei N. 852 de 30 de Outubro de 1923.

* Regulamento de 1924 - Decreto N. 867 de 11 de Março de 1924.

* Programma para o curso primario elementar e superior, 1924. 
Com base na legislação oficial apresentada ${ }^{8}$, é possível destacar as seguintes recomendações no que se refere aos métodos de ensino preconizados pela pedagogia nova, sintetizadas no Quadro 1.

Quadro 1 - Recomendações sobre métodos de ensino aos professores de ensino primário

\section{\begin{tabular}{l|l} 
DOCUMENTO & RECORTES
\end{tabular}}

Regulamento de 1912 Art. 72. "O ensino deve ser feito o mais praticamente possivel e pelo processo - Lei N. 605 de 24 de intuitivo" (SERGIPE, 1912, p. 24).

Setembro de 1912.

Decreto N. 571 de 19 Art. 86. "O ensino deve ser feito o mais praticamente possivel e pelo processo de Outubro de 1912. intuitivo" (SERGIPE, 1912, p. 36).

Lei N. 663 de 28 de Art. 72. "O ensino deve ser feito o mais praticamente possivel e pelo processo Julho de 1914. intuitivo (...)” (SERGIPE, 1914, p. 25).

Regulamento de 1916 Art. 208. "As licções sobre qualquer materia serão cingidas ao programma e - Decreto N. 630 de 24 de Abril de 1916. serão praticas, concretas", essencialmente empíricas e com exclusão completa de regras abstractas".

Paragrapho unico. "As faculdades da creança serão desenvolvidas gradual e harmonicamente por meio de processos intuitivos, tendo o professor sempre em vista desenvolver a observação" (SERGIPE, 1916, p. 244).

Lei N. 852 de 30 de Outubro de 1923.

Art. $1^{\circ}$. IX - "O ensino primario terá por objeto promover o desenvolvimento das faculdades moraes da creança, cultivar-lhe a vontade livre [...] Será, por conseguinte, intuitivo e pratico, por aspecto e por acção, partindo de realidades concretas á deducção, comprovação e generalização das idéas abstractas. Nestas condições, a tarefa do mestre será objectivada por um appello incessante e directo a espontaneidade intelectual, a attenção, comprehensão e raciocinio do alumno, no proposito do adiantamento geral e uniforme das classes." (SERGIPE, 1923, p. 30-31).

Regulamento de 1924 Art. 99. "O ensino publico primario terá por objeto promover o - Decreto N. 867 de desenvolvimento das faculdades moraes e intellectuaes da criança, cultivar-lhe 11 de Março de 1924. a vontade livre, preparar-lhe um physico sadio e assegurar-lhe os conhecimentos uteis á vida" (SERGIPE, 1924, p. 31).

Fonte: Quadro elaborado a partir dos Decretos, Leis, Regulamentos e Programas, aqui examinados.

\footnotetext{
${ }^{8}$ As fontes de pesquisa aqui apresentadas foram localizadas na Biblioteca Pública Epifânio Dórea, no Arquivo Público do Estado de Sergipe, no Instituto Histórico e Geográfico de Sergipe e no Diário Oficial do Estado de Sergipe, e disponibilizadas no Repositório de Conteúdo Digital do GHEMAT, isto é, no "[...] repositório virtual e aberto e institucionalizado, especificamente para armazenar fontes diversas, ensaios e pesquisas voltadas para a História da Educação Matemática" (COSTA, 2015, p. 33). Para maiores detalhes, ver: http://repositorio.ufsc.br/handle/123456789/1769.

${ }^{9}$ Segundo as normativas oficiais de Sergipe, a concepção de concreto pode ser evidenciada pela visualização de figuras/ilustrações e de situações-problema que tratam da vida da criança, isto é, do cotidiano para o âmbito escolar.
} 
Pelo exposto, constata-se que a recomendação era que o ensino fosse realizado de maneira prática e através do processo intuitivo, porém, não traz explicações conceituais sobre o que significavam esses termos.

Assim, na tentativa de compreender o significado de "prática", tomou-se como referência Leme da Silva (2015) com o alerta de ter, tal termo, “[...] nas diferentes vagas pedagógicas e nas distintas apropriações feitas pelos documentos oficiais" (LEME DA SILVA, 2015, p. 33), diversos significados.

No tocante aos saberes geométricos, segundo preceitos do método de ensino intuitivo, é possível inferir dois eixos significativos em que a prática pode ser destacada. Primeiro, na prática de um saber: “[...] a prática do desenho é a observação e reprodução de objetos naturais com suas imperfeições; e a prática da geometria recebe o desenho linear, ou seja, as construções com instrumentos de figuras geométricas, representando a precisão e perfeição" (LEME DA SILVA, 2015, p. 35-36).

Assim, no desenho natural, as coisas são observadas pelas crianças, para visualização e reprodução, desvinculadas da precisão e de propriedades das figuras geométricas e, no desenho linear, a prática está aliada à inserção de instrumentos de construção, como régua e compasso, por exemplo, ou seja, destaca-se a prática do manuseio.

Já no sentido de saber prático:

Os saberes geométricos associam-se às atividades práticas, nas quais, destacam-se: a atividade de medir, prática articulada com os elementos de agrimensura; a atividade de confeccionar trabalhos manuais, prática relacionada com a formação profissional e ainda a atividade de desenhar, prática que visa exercitar o olho e a mão. (LEME DA SILVA, 2015, p. 50).

Nesse âmbito, o saber está atrelado diretamente à prática do saber-fazer-com no dia a dia, de modo a concretizar os saberes na vida comum.

Consoante à ideia referente ao significado de prática, Pinto et al (2014) destaca o espírito prático como aquele relacionado aos saberes úteis para a vida:

[...] para atender necessidades da economia, útil para preparar mão de obra frente aos avanços da industrialização, com predominância das técnicas, hábitos e habilidades para finalidades imediatas, não mais a educação da mente e do raciocínio, mais um saber fazer auxiliado pelas novas linguagens necessárias às novas demandas profissionais (PINTO et al, 2014, p. 99).

Com ciência das possibilidades do significado prático do ensino no curso primário, cabe indagar: E o entendimento do ensino intuitivo prescrito? 
Para compreender o método prescrito, em diversos documentos analisados eram indicados aos professores primários, adotarem o manual Primeiras Lições de Coisas, escrito por Norman Allison Calkins ${ }^{10}$ e traduzido por Rui Barbosa, para servir de suporte e apoio no que diz respeito ao método citado.

No supracitado manual, é possível identificar alguns princípios fundamentais, considerados pelo autor como essenciais ao processo de ensino intuitivo. Para Calkins $(1886 / 1950)$,

O primeiro passo preparatório para a educação de crianças convém que seja estudar a natureza do espírito e sua condição na puerícia, seus modos naturais de desenvolvimento e os processos melhor adaptados a disciplinar-lhe acertadamente as faculdades (CALKINS, 1886/1950, p. 29).

Nesse sentido, alguns princípios são destacados para o ensino envolta das lições de coisas. Em um desses, destaca o autor que "[...] o mais natural e saudável incentivo para obter, entre crianças, a atenção e aquisição de conhecimentos, é associar a recreação ao ensino" (CALKINS, 1886/1950, p. 30). Talvez, por conta disso seja possível observar, em documento escrito por Helvécio de Andrade, Diretor da Instrução Públicas do Estado de Sergipe, instruções consideradas Para a bôa macha do ensino primario, ao prescrever:

[...] que os professores promovam passeios aos domingos com seus alumnos ao campo ou jardins públicos ou particulares, e aproveitem essas oportunidades [...] Nesses passeios obtem-se bons exercicios de educação dos sentidos intellectuais, avaliando distancias, calculando areas, [...] calculos cuja exactidão ou erro o professor verificará (ANDRADE, 1914, p. 4-5).

Dessa forma, a recomendação era para que os mestres promovessem passeios que possibilitassem ser relacionados aos conteúdos primários, pois, a instrução associada à recreação produziria atenção e prazer na aprendizagem, aguçando a curiosidade e possibilitando ao aluno o avanço do conhecimento em seu próprio cotidiano.

Outro princípio fundamental era que "[...] o processo natural de ensinar deve partir do simples para o complexo; do que se sabe, para o que se ignora; dos fatos, para as causas; das coisas, para os nomes; das idéias, para as palavras; dos princípios, para as regras"

\footnotetext{
${ }^{10}$ Segundo Valdemarin (2006), o manual de Calkins é apresentado na Exposição Universal de Filadélfia, realizada em 1876, sendo recomendado por Ferdinand Buisson em seu relatório ao governo francês como a melhor coleção de lições de coisas já elaborada, motivando inúmeras traduções, em que, além desta, destacamse uma versão japonesa em 1877 e duas versões para o espanhol em 1872 e 1879. Em sua $40^{a}$ edição, é vertido e adaptado as condições de nosso idioma pelo Conselheiro Ruy Barbosa, em 1886, cujo texto é republicado em 1950 pelo Ministério da Educação e Saúde, no volume 13 das Obras Completas de Rui Barbosa.
} 
(CALKINS, 1886/1950, p. 31). Este princípio, em âmbito geral, parece permear as indicações postas no quadro 9.

Além disso, cabe destacar a importância da observação tida na instrução, ou melhor, dos sentidos, pois,

\begin{abstract}
Os sentidos fornecem ao espírito os meios de comunicação com o mundo exterior. Mediante sensações logra o entendimento a percepção dos objetos circunjacentes. A percepção leva a concepções ou idéias, que a memória retém, ou evoca. A imaginação apodera-se das idéias constituídas mediante a percepção, combina-as, e imprime-lhes novas formas. $\mathrm{O}$ raciocínio procede ao exame das idéias por método mais definidos, resultando dessa investigação o juízo. Outrossim, das sensações procede a percepção; a atenção, fixada no que se percebeu, leva a observação. Enfim, graças à observação, à comparação e à classificação das experiências e dos fatos, alcançamos o conhecimento. (CALKINS, 1886/1950, p. 31).
\end{abstract}

Assim, notam-se os passos, ou melhor, as "principais forças de inteligência" que, para Calkins (1886/1950), devem ser empregadas a fim de se adquirir o conhecimento e a inteligência, atingindo as faculdades mentais da criança na formação de suas ideias.

Em suma, os procedimentos de ensino apresentados por Calkins (1886/1950), têm início na educação dos sentidos a fim de preparar os alunos para a observação acurada, pois, acredita-se que esta produz ideias claras e distintas que, acrescidas da imaginação e do raciocínio, levam a criança ao desenvolvimento da capacidade de julgamento e de discernimento, com a aprendizagem evoluindo concomitantemente ao desenvolvimento físico e intelectual.

Em acordo com Calkins (1886/1950), a autora Valdemarin (2006), entende o método intuitivo como instrumento pedagógico capaz de reverter a ineficiência do ensino escolar em que “[...] novos materiais, criação de museus pedagógicos, variação de atividades, excursões pedagógicas, estudo do meio etc.” (VALDEMARIN, 2006, p. 91), assim, apresentam-se como locus de mudanças para adequar a escola ao projeto político modernizador.

Nesse sentido, cabe trazer uma apresentação sobre o primeiro ano de curso primário dos saberes aritméticos, exposta no quadro 2, relatado pelos Programas de 1915, 1916 e 1917, pois, neles o saber era posto de maneira diferenciada dos demais, isto é, os programas não apresentam, de maneira direta e objetiva, os SEM a serem estudados. Ao que parece, eles surgem na descrição de uma lição, estando em meio à prática pedagógica a ser realizada pelo professor primário, a saber: 
Quadro 02 - Proposta apresentada pelos Programas de 1915, 1916, 1917 ao Ensino de Aritmética

\begin{tabular}{|c|c|}
\hline $1^{\circ}$. ANNO & RECOMENDAÇÕES \\
\hline $\begin{array}{l}\text { Primeiros exercicios } \\
\text { (Phase preliminar) }\end{array}$ & 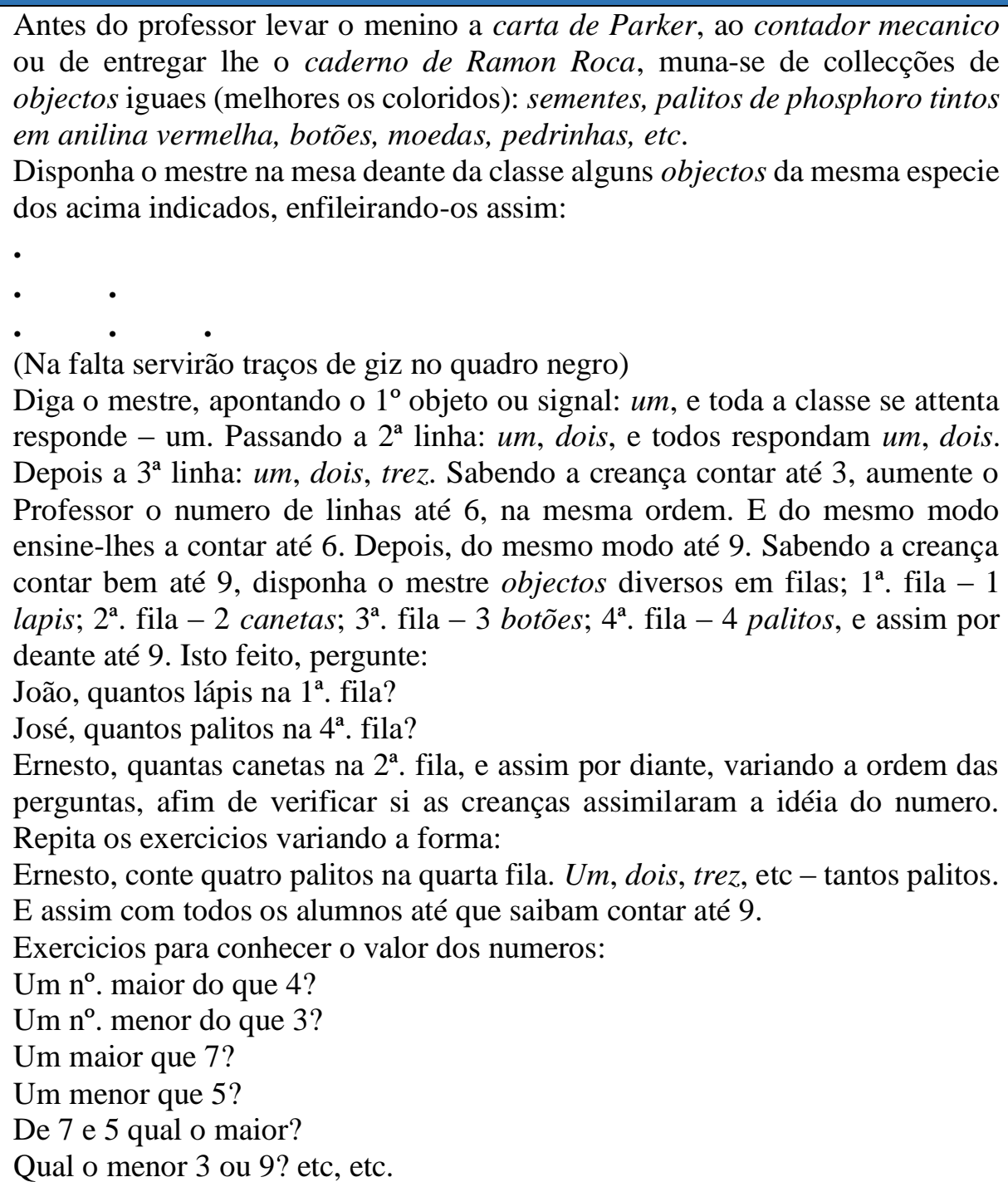 \\
\hline
\end{tabular}

Fonte: Quadro elaborado a partir dos Programas de 1915, 1916 e 1917, contidos no Acervo da Biblioteca Pública Epifânio Dória e disponibilizados no repositório virtual do GHEMAT.

Assim, nota-se pelo apresentado no quadro 2, que o conteúdo proposto era indicado por meio de uma listagem de procedimentos que deveriam ser seguidos pelo mestre para alcançar a aprendizagem dos alunos, cujos passos são apresentados de maneira semelhante nas duas primeiras fases dos respectivos programas.

Percebe-se que no documento há menção a diversos objetos a serem utilizados na contagem e comparação de quantidades para se construir a ideia de número, como: sementes, palitos, botões, moedas, pedrinhas, lápis, caneta, entre outros. 
Verifica-se também, referencias as Cartas de Parker $^{11}$ e contadores mecânicos ${ }^{12}$, recomendados após a utilização de objetos simples para a contagem. Materiais semelhantes a esses são citados por Valdemarin (2006), difundidos no período de renovação pedagógica, como: "[...] caixas de ensino das cores e das formas, gravuras, coleções, objetos variados de madeira, aros, linhas, papéis etc. em substituição ao velho livro de textos para serem memorizados" (VALDEMARIN, 2006, p. 91).

Assim, materiais como as sementes, os torninhos ${ }^{13}$, os pauzinhos, entre outros, apresentavam-se como indispensáveis ao ensino primário, pois, a partir do método adotado,

[...] as lições são organizadas tendo por critério a importância atribuída a cada um dos sentidos para a aquisição do conhecimento, iniciando-se pelos conteúdos mais adequados à percepção visual e finalizando com aqueles que têm no tato seu suporte cognitivo (VALDEMARIN, 2006, p. 101).

Dessa maneira, com a adoção do método de ensino intuitivo perante a pedagogia moderna, pretendia-se educar a criança a partir de novos padrões intelectuais que se fundamentavam em nova concepção do conhecimento, originado pelas ideias nos sentidos humanos, como enfatiza Calkins (1886/1950), a fim de formar indivíduos que usem menos a memória e mais a razão, e que valorizem a observação e o julgamento próprios como meio de construção do conhecimento e implementação das atividades produtivas. Daí a importância dos materiais, possibilitando uma reelaboração de métodos, conteúdos e procedimentos didáticos.

\section{ALGUMAS CONSIDERAÇÕES: ENTRE PEDAGOGIAS E MATERIAIS}

Ao realizar um exame sobre as fontes para se compreender como os materiais de ensino eram indicados nas prescrições legais de Sergipe, foi possível identificar os modos e tratamentos que eram destinados aos materiais.

\footnotetext{
11 "Constituem um conjunto de gravuras cujo fim é o de auxiliar o professor a conduzir metodicamente o ensino, sobretudo, das quatro operações fundamentais. Junto de cada gravura, há uma orientação ao professor de como deveria dirigir-se à classe de modo a fazer uso de cada uma delas e avançar no ensino da Aritmética" (VALENTE, 2013, p. 03).

12 Tratava-se de ábacos, considerando seus diversos modelos e variantes, aparelho didático "[...] de base exclusiva aos exercícios de numeração, sem perder de vista as orientações do método intuitivo" (PAIS, 2011, p. 03).

${ }^{13}$ Em acordo com Pinheiro (2013), os torninhos ou tornos de sapateiros, como eram conhecidos, eram pedaços de madeira em forma de pauzinhos utilizados, por muito tempo, como auxílio para o ensino concreto de Aritmética.
} 
Para se alcançar a modernidade pedagógica, criam-se grupos escolares em diversos estados do país cujo principal intento consistia em modificar as bases pelas quais o ensino era realizado, mediante o emprego de novo método de ensino: o intuitivo.

Assim, na pedagogia nova, o método de ensino intuitivo é indicado tendo como princípios o ensino pelos sentidos, pela realidade e pela intuição como principal instrumento de aprendizagem.

Pela proposta metodológica, o ensino deveria partir da observação, do visual de objetos para o manuseio destes. Por meio das fontes examinadas, é possível afirmar que haviam prescrições para que, em alguns momentos, os professores se munissem de objetos para a visualização dos alunos e, em outros, a indicação era para que os alunos manuseassem os materiais de ensino, repudiando-se o ensino pela memorização e abstração, sem a devida compreensão.

Em suma, é possível destacar que as propostas recomendavam materiais que, com o passar dos anos eram intensificados, cujos exercícios buscavam o aprimoramento da observação e inteligência, e que permitissem a reprodução de construções, móveis e utensílio familiares, aliados ao prazer e satisfação na aprendizagem, isto é, exercícios que permitissem a materialização na prática.

Mas, cabe frisar, que aqui está posto um recorte histórico acerca dos materiais de ensino no primário sergipano, aliado a um método de ensino que servia como base referencial ao modo como a modernidade educacional pudera ser alcançada. Tais exclamações podem ser melhor averiguadas ampliando-se o marco investigado, ou ainda, com a possibilidade de se inventariar fontes que aqui não puderam ser examinas. Entretanto, aqui coube apontar informações sobre pedagogias e materiais, não obstante de pronto e acabado, afinal, isto é história.

\section{REFERÊNCIAS}

ANDRADE, H. de. Instrucções para a bôa marcha do ensino primário. Aracaju: Typ. D' O Estado de Sergipe, 1914. Acesso em 17 de Abril de 2015. Disponível em: https://repositorio.ufsc.br/xmlui/handle/123456789/133885.

AZEVEDO, C. B. de. Grupos Escolares em Sergipe (1911-1930): cultura escolar, civilização e escolarização da infância. Natal, RN: EDUFRN - Editora da UFRN, 2009.

CALKINS, N. A. Primeiras lições de coisas. Rio de janeiro: Ministério da Educação e Saúde, 1886/1950. [Volume XIII, tomo I das Obras completas de Rui Barbosa]. 
CARVALHO, M. M. C. de. Reformas da Instrução Pública. In: LOPES, E. M. T. et al. 500 anos de Educação no Brasil. Belo Horizonte: Autêntica, 2003.

CHERVEL, A. História das disciplinas escolares: reflexões sobre um campo de pesquisa. vol. 2. Teoria \& Educação. Porto Alegre, 1990.

COSTA, D. A. da. Repositório. In: VALENTE, Wagner Rodrigues (org.) Cadernos de Trabalho. São Paulo: Ed. Livraria da Física, 2015.

JULIA, D. A cultura escolar como objeto histórico. Revista Brasileira de História da Educação. n. 1. Campinas, SP: SBHE, 2001. Acesso em 28 de Maio de 2014. Disponível em www.rbhe.sbhe.org.br/index.php/rbhe/article/download/273/281

LEME DA SILVA, M. C. Caminhos da pesquisa, caminhos pelos saberes elementares geométricos: a busca da historicidade da prática nos estudos da educação matemática no Brasil. In: VALENTE, W. R. (orgs.). Prática - Cadernos de Trabalho. São Paulo: Ed. Livraria da Física, 2015.

LIMA, G. S. A Cultura Material Escolar: desvelando a formação da Instrução de Primeiras Letras na Província de Sergipe (1834-1858). Dissertação de Mestrado em Educação. 159f. Universidade Federal de Sergipe: PPGED/UFS, 2007. Acesso em 22 de Setembro de 2014. Disponível em: https://bdtd.ufs.br/handle/tede/1722

NASCIMENTO, J. C. Notas para uma Reflexão acerca da Escola Primária Republicana em Sergipe (1889-1930). In: ARAÚJO, J. C. S.; SOUZA, R. F. de.; PINTO, R. N. Escola Primária na Primeira República (1889-1930): subsídios para uma história comparada. Araraquara, SP: Junqueira\&Marin, 2012.

PAIS, L. C. Difusão de materiais para o ensino primário da aritmética na exposição pedagógica do Rio de Janeiro (1883). Anais do VI Congresso Brasileiro de História da Educação. Vitória, ES: UFES, 2011. Acesso em 20 de Fevereiro de 2016. Disponível em: http://www.sbhe.org.br/novo/congressos/cbhe6/anais_vi_cbhe/.../1089.doc

PINHEIRO, N. V. L. Escolas de Práticas Pedagógicas Inovadoras: Intuição, Escolanovismo e Matemática Moderna nos primeiros anos escolares. Dissertação de Mestrado em Educação e Saúde na Infância e na Adolescência. 155f. Universidade Federal de São Paulo: PPG Educação e Saúde na Infância e na Adolescência, 2013. Acesso em 07 de Janeiro de 2014. Disponível em: https://repositorio.ufsc.br/bitstream/handle/123456789/104911/Nara_Vilma_Lima_Pinheir o_Disserta\%C3\%A7\%C3\%A3o_2013.pdf?sequence $=3$

PINTO, N. B. et al. A Aritmética Prática nos Programas de Ensino Primário do Estado do Paraná (1901-1963). In: COSTA, D. A. da.; VALENTE, W. R. (orgs.). Saberes matemático no curso primário: o que, como e por que ensinar? São Paulo: Ed. Livraria da Física, 2014.

SAVIANI, D. As Concepções Pedagógicas na História da Educação Brasileira. História, Sociedade e Educação no Brasil - Revista HISTEDBR (1986-2006). São Paulo, SP: Faculdade de Educação/Unicamp, 2006. Acesso em 22 de Abril de 2016. Disponível em: http://www.histedbr.fe.unicamp.br/navegando/artigos_frames/artigo_036.html 
SOUZA, R. F. de. Espaço da Educação e da Civilização: origens dos grupos escolares no Brasil. In: SAVIANI, Dermeval. et al. O Legado Educacional do Século XIX. 2. ed. rev. e ampl. Campinas, SP: Autores Associados, 2006.

VALDEMARIN, V. T. O método Intuitivo: os sentidos como janelas e portas que se abrem para um mundo interpretado. In: SAVIANI, Dermeval et al. O legado educacional do século XIX. 2. ed. e ampl. Campinas, SP: Autores Associados, 2006.

VALENTE, W. R. O ensino intuitivo de Aritmética e as Cartas de Parker. V Congresso Brasileiro de História da Educação. Aracaju, SE: UFS, 2008. Acesso em 14 de Junho de 2015. Disponível em: http://sbhe.org.br/novo/congressos/cbhe5/pdf/528.pdf

\section{Publicações Oficiais}

SERGIPE. Regulamento de 1912. Aracaju: Imprensa Official, 1912. Acesso em 07 de Abril de 2015. Disponível em: https://repositorio.ufsc.br/xmlui/handle/123456789/124889.

. Decreto de N. 571, de 19 de outubro de 1912. Aracaju: Imprensa Official, 1912.

Acesso em 09 de Abril de 2015. Disponível em:
http://repositorio.ufsc.br/handle/123456789/103584.

Programmas para o ensino primário: especialmente os grupos escolares do estado de Sergipe. Aracaju: Typ. D' O Estado de Sergipe, 1912. Acesso em 13 de Abril de 2015. Disponível em: https://repositorio.ufsc.br/xmlui/handle/123456789/124884.

. Coleção de Leis e Decretos de 1914 - Lei nº 663 de 28 de julho de 1914. Aracaju: Imprensa Official, 1914. Acesso em 24 de Abril de 2015. Disponível em: https://repositorio.ufsc.br/handle/123456789/103585.

Programmas para o curso primário nos grupos escolares e escolas isoladas do estado de Sergipe, 1915. Aracaju: Typ. D' O Estado de Sergipe, 1915. Acesso em 12 de Maio de 2015. Disponível em: https://repositorio.ufsc.br/xmlui/handle/123456789/124882.

. Programmas para o curso primário nos grupos escolares e escolas isoladas do estado de Sergipe, 1916. Aracaju: Typ. D' O Estado de Sergipe, 1915. Acesso em 19 de Maio de 2015. Disponível em: https://repositorio.ufsc.br/handle/123456789/116813.

. Decreto N. 630, de 24 de abril de 1916. Aracaju: Imprensa Official, 1916.

Acesso em 20 de Maio de 2015. Disponível em:
https://repositorio.ufsc.br/handle/123456789/104705.

. Programmas para o curso primário nos Grupos Escolares e escolas isoladas do estado de Sergipe. Aracaju: Imprensa Official, 1917. Acesso em 23 de Maio de 2015. Disponível em: http://repositorio.ufsc.br/handle/123456789/103591.

. Lei n 852 em 30 outubro de 1923. Aracaju: Imprensa Official, 1923. Acesso em 26 de Maio de 2015. Disponível em: https://repositorio.ufsc.br/handle/123456789/104704. 
. Programma para o curso primário elementar e superior do Estado de Sergipe, 1924. Aracaju: Imprensa Official, 1924. Acesso em 01 de Junho de 2015. Disponível em: https://repositorio.ufsc.br/xmlui/handle/123456789/124883.

. Regulamento de 1924. Aracaju: Imprensa Official, 1924. Acesso em 27 de Maio de 2015. Disponível em: https://repositorio.ufsc.br/handle/123456789/104709. 